\title{
Strain and crack development in continuous reinforced concrete slabs subjected to catenary action
}

\author{
Dirk Gouverneur ${ }^{\mathrm{a}}$, Robby Caspeele* and Luc Taerwe ${ }^{\mathrm{b}}$ \\ Department of Structural Engineering, Ghent University, Technologiepark-Zwijnaarde 904, \\ 9052 Ghent, Belgium
}

(Received February 28, 2013, Revised September 1, 2014, Accepted October 17, 2014)

\begin{abstract}
Several structural calamities in the second half of the 20th century have shown that adequate collapse-resistance cannot be achieved by designing the individual elements of a structure without taking their interconnectivity into consideration. It has long been acknowledged that membrane behaviour of reinforced concrete structures can significantly increase the robustness of a structure and delay a complete collapse. An experimental large-scale test was conducted on a horizontally restrained, continuous reinforced concrete slab exposed to an artificial failure of the central support and subsequent loading until collapse of the specimen. Within this investigation the development of catenary action associated with the formation of large displacements was observed to increase the ultimate load capacity of the specimen significantly. The development of displacements, strains and horizontal forces within this investigation confirmed a load transfer process from an elastic bending mechanism to a tension controlled catenary mechanism. In this contribution a special focus is directed towards strain and crack development at critical sections. The results of this contribution are of particular importance when validating numerical models related to the development of catenary action in concrete slabs.
\end{abstract}

Keywords: concrete; slabs; robustness; membrane actions; real-scale testing

\section{Introduction}

Various structural failures in the second half of the 20th century such as the collapse of the apartment building at Ronan Point (UK) in 1968 or several terrorist attacks all over the world have demonstrated that adequate collapse-resistance cannot be achieved by designing the individual elements of a structure without considering their interconnectivity. Consequently, structural engineers are faced with the fact that the connections between different members have a considerable effect on the safety level and their vulnerability to progressive collapse.

The design of reinforced concrete structures is usually based on small deformation theories. The different design methods aim at keeping deflections and crack widths within adequate serviceability limits. However, the risk of a structural failure, increases in accidental situations,

*Corresponding author, Professor, E-mail: Robby.Caspeele@UGent.be

${ }^{\mathrm{a}} \mathrm{Ph} . \mathrm{D}$.

${ }^{\mathrm{b}}$ Professor 
typically combined with the occurrence of large deflections. Under these conditions the structural interaction between the different elements becomes important in order to provide alternate load paths.

The European Standard EN 1990 (2002) refers to the following requirement regarding robustness of a structure: "A structure shall be designed and executed in such a way that it will not be damaged by events such as explosion, impact and the consequence of human errors to an extent disproportionate to the original cause".

Moreover, EN 1991-1-7 (2006) points out three strategies to limit the implication of accidental situations:

- to design key load-bearing members in order to withstand nominal accidental action effects

- to limit damages due to the collapse of a load-bearing member through alternate load paths

- to apply prescriptive design and detailing rules.

When applying the second mentioned method, one should be able to account for the development of catenary forces within a reinforced concrete structure as this considerably influences the resistance of structural components (Yu and Tan 2011). The effect of these forces on the load-carrying capacity and the associated development of strains and cracks are subject of this investigation.

The consideration of tensile membrane action can yield a considerable advantage in case of ULS verifications, especially in case of accidental situations for which the residual bearing capacity of the member or the system in which an accidental load path has been activated, has to be determined. As the deformations during the occurrence of tensile membrane action are very high (which corresponds to the occurrence of plastic hinges and large rotation angles), the relevance for the consideration of tensile membrane behaviour for SLS related problems seems of minor practical importance unless one wants to investigate e.g., deformations in case of emergency interventions after an accidental event.

\section{Membrane action}

Very large deflections may occur in the floor slabs of a building without resulting in the collapse of the structure. It was found that this favourable behaviour is due to membrane action. It plays a considerable role in increasing the load carrying capacity of floor slabs in accidental load situations above the commonly adopted design values based solely on flexural behaviour (Li et al. 2007).

The effect of membrane behaviour has been acknowledged for a long time already. In 1921, Westergaard and Slater (1921) examined membrane behaviour in several full-scale tests on floor panels. Destructive tests conducted at the dental hospital in Johannesburg by Ockleston in 1955 revealed a significant increase in the load-carrying capacity of the floor panel system. Subsequently, the influence on the observed in-plane membrane forces on the ultimate capacity became an active field of investigation (Bailey et al. 2008).

The most beneficial test results published previously on the topic of membrane action were related to the behaviour at small displacements of slabs with horizontal restraint along the edges. These types of concrete slabs are subjected to compressive membrane action, which allows a significant enhancement of the load-carrying capacity. The membrane action of concrete slabs occurring at large displacements, which is typically named tensile membrane action, includes slabs with horizontal restraint and vertical support around its edges as well as slabs that are free to move 


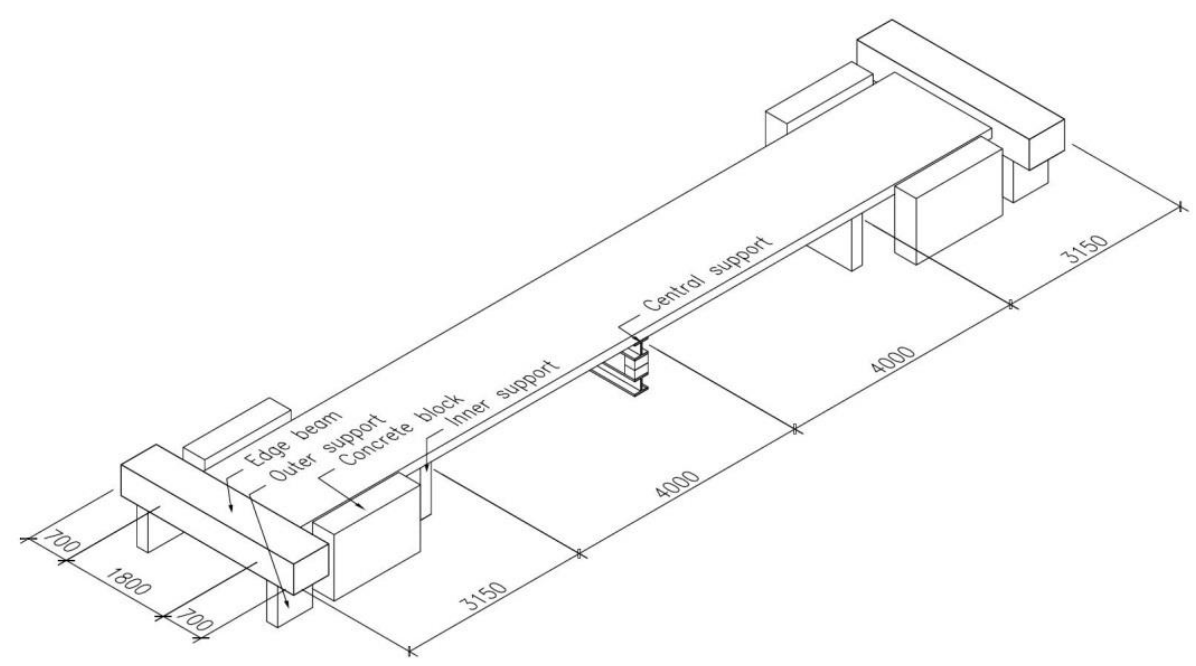

Fig. 1 Test set-up configuration

horizontally (Bailey 2001). The first systematic analytical approach was provided by Wood in 1961. He studied the behaviour of a rectangular slab panel with perfect edge restraint. In earlier stages of the loading range, compressive membrane forces are induced due to the horizontal restraint against outward movement along the slab edges. As a result, the maximum load which can be achieved is significantly higher than the one predicted by Johansen's yield line theory (1962). After reaching this maximum load under compressive membrane force, the supported load decreases with further displacements as a result of the reduction in compressive membrane force. Subsequently, the membrane force in the central region of the slab changes from compression to tension. As the slab boundary restraints begin to resist inward movement of the edges the loaddeflection curve increases accordingly. Cracks penetrate the full thickness of the slab and the yielding of steel spreads throughout this region. It was observed that the reinforcement acts as a tensile membrane carrying the load. With further deflection, the carried load increases until the reinforcement fractures.

Research into compressive membrane action at small displacements has recently been investigated more profoundly because of its importance when quantifying the underestimation of the structural capacity due to membrane action (e.g. Amir et al. 2012 and Muthu et al. 2007). However, investigations into tensile membrane action at large displacements are rather scarce after the pioneering work in the 1960s by researchers such as Wood (1961), Park (1964) and Hayes (1968).

\section{Experimental program}

\subsection{Test set-up}

The experimental investigation involved the testing of a large-scale specimen as illustrated in Fig. 1. The flexural reinforcement was applied continuously over the entire length of the specimen without curtailment and comprised 16 bars with a nominal diameter of $10 \mathrm{~mm}$ for the bottom and 


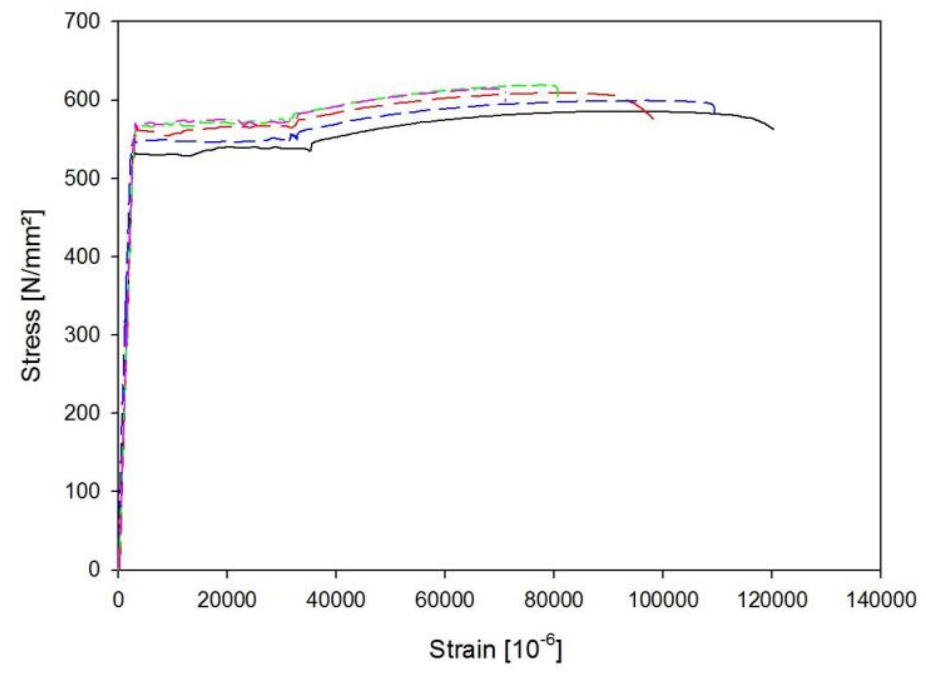

Fig. 2 Stress-strain behaviour of the reinforcement S500
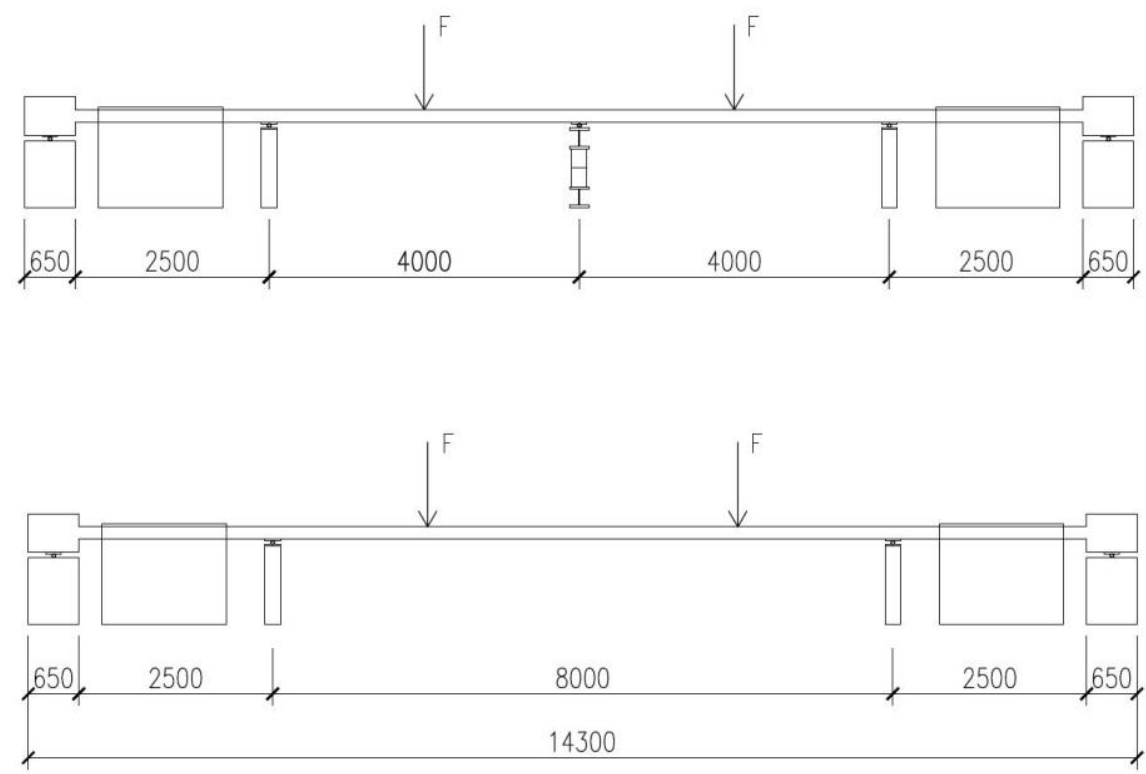

Fig. 3 Loading scheme before (a) and after (b) removal of the central support

top longitudinal reinforcement, respectively, with a concrete cover of $20 \mathrm{~mm}$. For the slab specimen under investigation in this contribution, both the top and bottom longitudinal reinforcement was continuous over the entire length of the slab (14,3 m). Reinforcement bars S500 were used and 5 tensile tests were performed in order to characterize the actual stress-strain behaviour (see Fig. 2). A detailed description of the test set-up is given in Gouverneur et al. (2013).

The testing procedure was subdivided into three different loading phases, whereas phase 1 involved the gradual application of line loads until a service load of $60 \mathrm{kN}$ (Fig. 3(a)). 


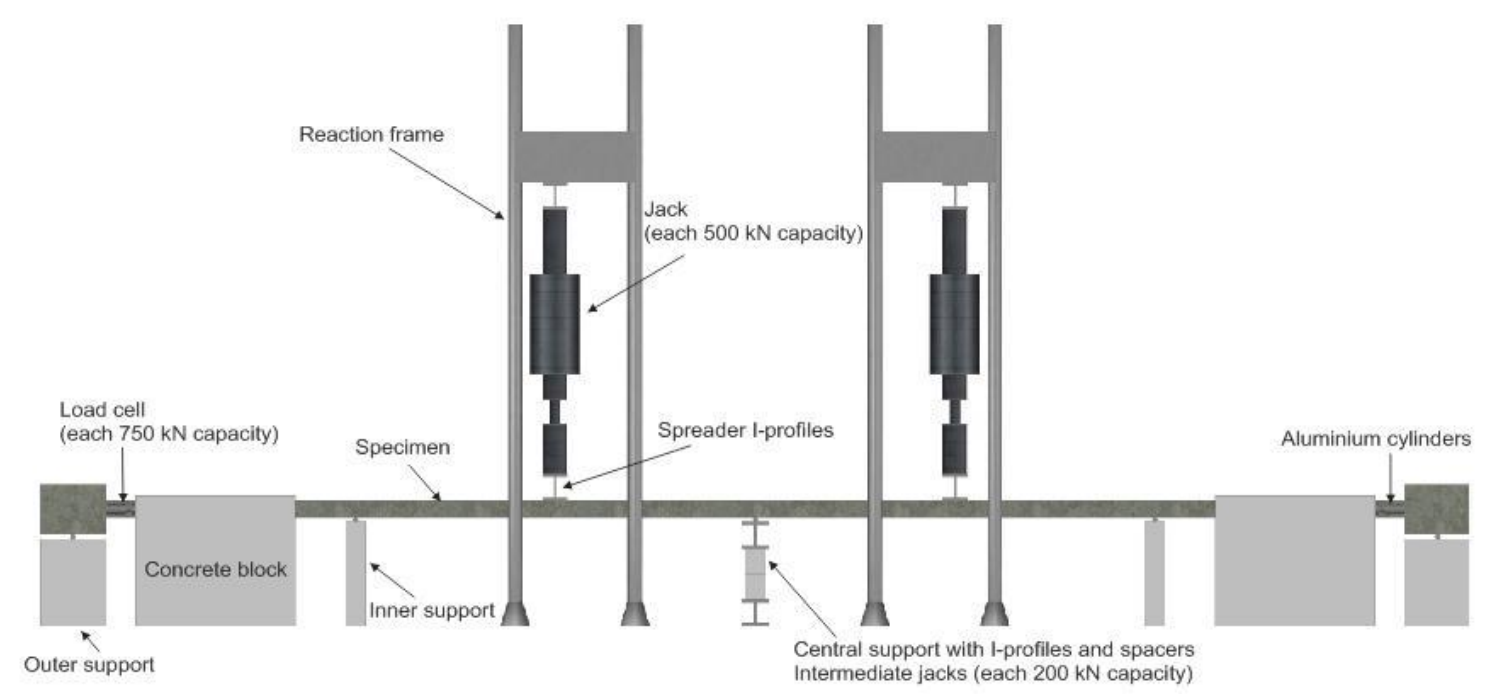

Fig. 4 Test set-up with loading devices

Subsequently, the load was removed again. In a second phase, the central support of the specimen was gradually removed. In a third phase (Fig. 3(b)), the load was increased until the collapse of the slab strip.

\subsection{Test apparatus and instrumentation}

Fig. 4 illustrates the test set-up with its loading devices.

The load was applied using two identical jacks with a capacity of $500 \mathrm{kN}$ each pushing on mortar embedded spreader I-profiles in the middle of each of the inner spans. Thus, the distance between the two line loads was $4 \mathrm{~m}$. The jacks reacted against a reaction frame anchored in the laboratory's floor. At the central support, two jacks with a capacity of $200 \mathrm{kN}$ each were positioned in between concrete cube spacers. On one side of the specimen, two load cells with a capacity of $750 \mathrm{kN}$ each were located between the restraining concrete blocks and the specimen's edge beam. As such, horizontal compression forces could be measured. At the opposite side, however, aluminium cylinders with the same axial stiffness as the load cells were used in order to withstand the horizontal membrane force.

Multiple displacement transducers (LVDTs) and dial gauges were positioned at various points in order to record vertical and horizontal displacements. In addition, demountable mechanical strain gauges (DEMECs) and electronic deformation gauges were used to measure strains at midspan (central support), under the loads as well as over the inner supports. Fig. 5 illustrates schematically the location of the electronic and manual strain measuring devices at the supports (side view).

\subsection{Removal of the central support}

The loss of a vertical support is a scenario that has often been considered when assessing the robustness of a structure. Due to such accidental events, stresses are redistributed and an alternate 


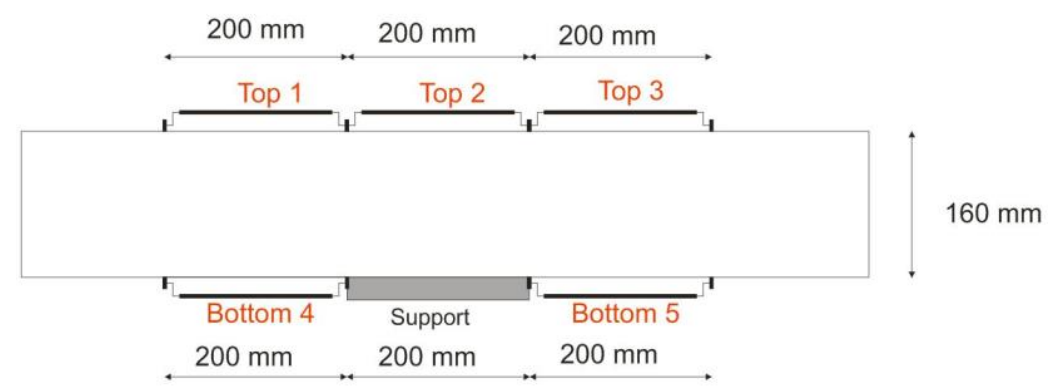

(a) Electronic deformation gauges

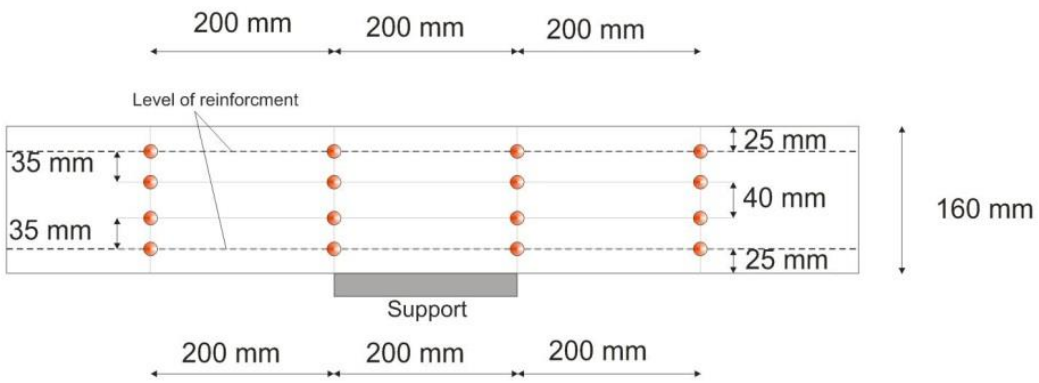

(b) Demountable mechanical strain gauges (DEMEC)

Fig. 5 Electronic and manual strain measuring devices at the supports

load path has to be established in order to withstand the load.

The artificial failure of the central support was established by slightly pushing up the jacks beneath the central support. As such, the plate bent slightly upwards (less than $1 \mathrm{~mm}$ ) and the concrete cube spacers could be removed. Accordingly, the reacting force in mid-span was carried by the central jacks only and reaction forces could be measured. Subsequently, the pressure in these jacks was gradually reduced and reaction forces at the central support were decreased accordingly until disconnection of the central support from the slab. When the reaction force in the jacks became zero, the two inner spans of $4 \mathrm{~m}$ were transformed into one single span of $8 \mathrm{~m}$ (see Fig. 3(b)).

\section{Experimental results and discussion}

\subsection{Displacements}

Fig. 6 illustrates the deflection behaviour during phase 1. The load was gradually applied until service load $(60 \mathrm{kN})$ at a deflection of $2.5 \mathrm{~mm}$. Subsequently, the load was reduced ending in a residual deflection of $0.8 \mathrm{~mm}$ at $0 \mathrm{kN}$.

Phase 2 of the experimental investigation included the artificially simulated failure of the central support. Fig. 7 shows the reaction force at the central support. When the reaction force at the central support was removed, a local deflection of $12.3 \mathrm{~mm}$ was observed. Note that the small platforms observable in the descending branch of the curve (Fig. 7) are due to the time needed for 


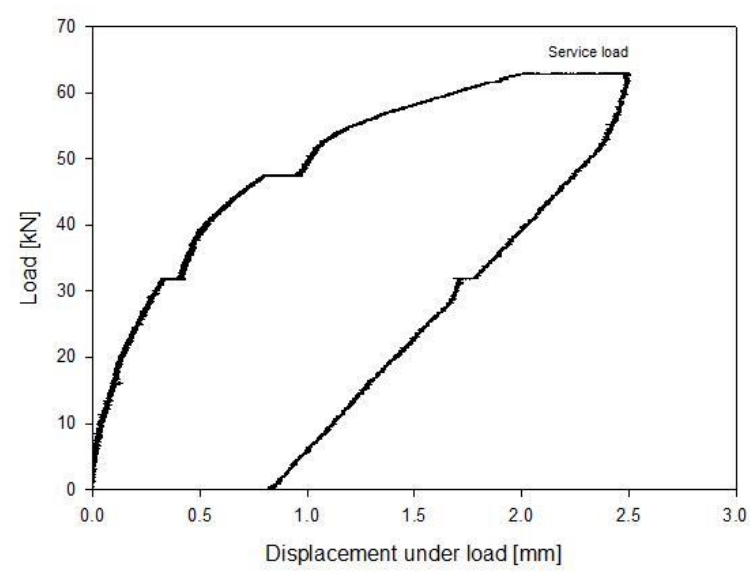

Fig. 6 Load-displacement behaviour, Phase 1

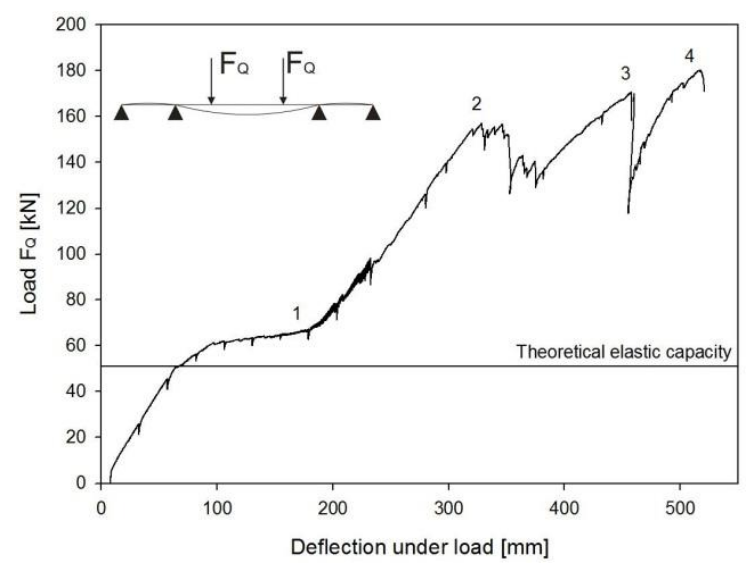

Fig. 8 Load-displacement behaviour, Phase 3

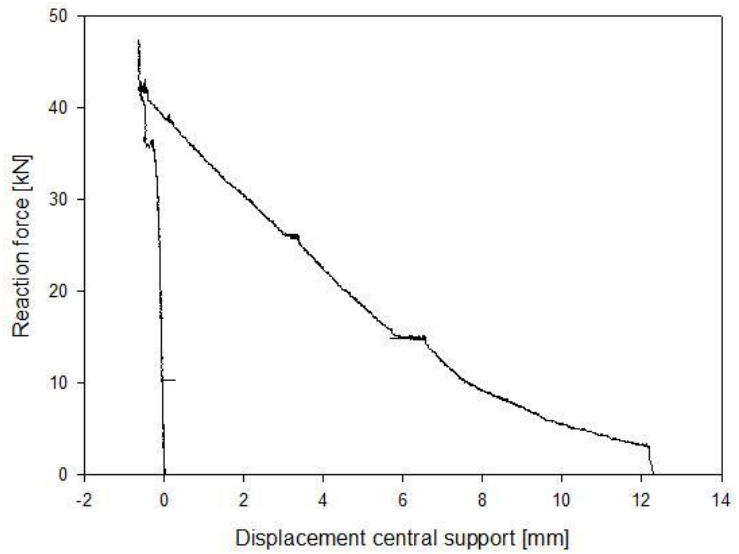

Fig. 7 Load-displacement behaviour, Phase 2

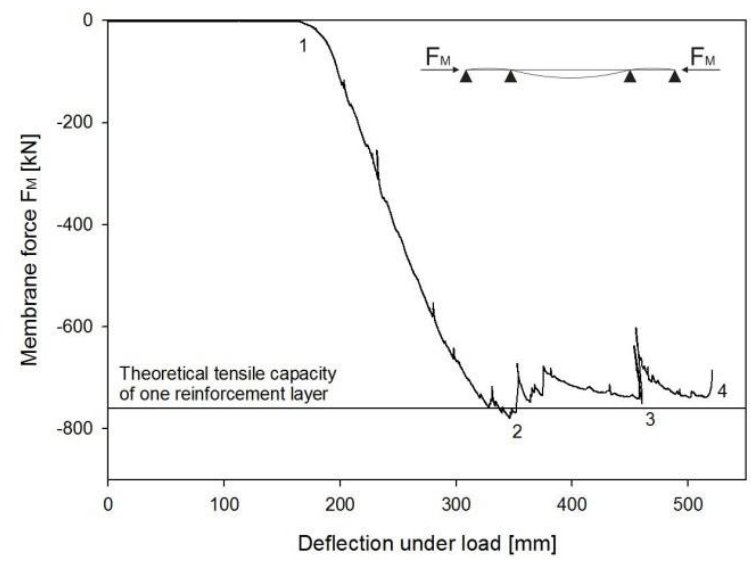

Fig. 9 Development of membrane force, Phase 3

manual measurements during which the reaction force in the central span was kept at the same level.

Figs. 8 and 9 show the load-displacement behaviour of the specimen in phase 3 (Fig. 8 ) and the development of the tensile membrane force (Fig. 9). The line loads were applied displacement controlled. Tensile membrane actions started to act at a deflection of around $160 \mathrm{~mm}$ (point 1) as a result of the restraint of inward movement, thus enhancing significantly the load-carrying capacity of the specimen. The rupture of the top reinforcement bars over the left support (point 2) as well as over the right support (point 3) initiate a decrease in the slope of the load-displacement graph. The rupture of the bottom reinforcement over the right support at a deflection of $525 \mathrm{~mm}$ at the load application points (645 mm at mid-span) at a load level of $180 \mathrm{kN}$ resulted in the failure of the specimen (point 4). Further, the theoretical elastic capacity corresponding to the moment $M_{y}=A_{s} f_{y} h$ with $A_{s}$ the cross sectional area of one reinforcement layer, $f_{y}$ the yield strength of the reinforcement and $\mathrm{h}$ the lever arm $(135 \mathrm{~mm})$ is indicated in Fig. 8 as a horizontal line. A maximum horizontal tensile force of up to $780 \mathrm{kN}$ was measured (see Fig. 9).

Considering the experimentally obtained stress-strain diagrams of the reinforcement (Fig. 2) 
and the cross sectional area of one reinforcement layer $A_{s}=1257 \mathrm{~mm}^{2}$, the values $A_{s} f_{y}=$ $697 \mathrm{kN}$ and $A_{s} f_{t}=760 \mathrm{kN}$ (see horizontal line in Fig. 9) are obtained (with $f_{y}=555 \mathrm{MPa}$ the yield strength and $\mathrm{f}_{\mathrm{t}}=605 \mathrm{MPa}$ the tensile strength) of the reinforcement obtained as the mean values from experimental results described in section 3.1.

\subsection{Strain development at the central support/mid-span}

The development of strains at the top and bottom fibres of the mid-span section is given in Fig. 10 (digital measurements) and the strain distribution over the slab depth in Fig. 11 (mechanical measurements).

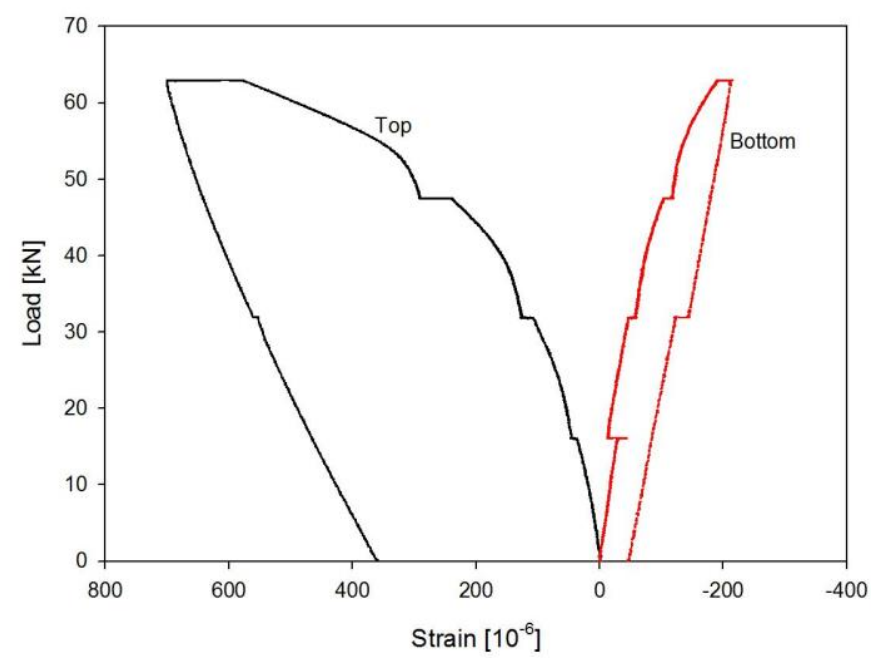

Fig. 10 Strain development measured by electronic deformation gauges (Fig. 5a) at the central support, Phase 1

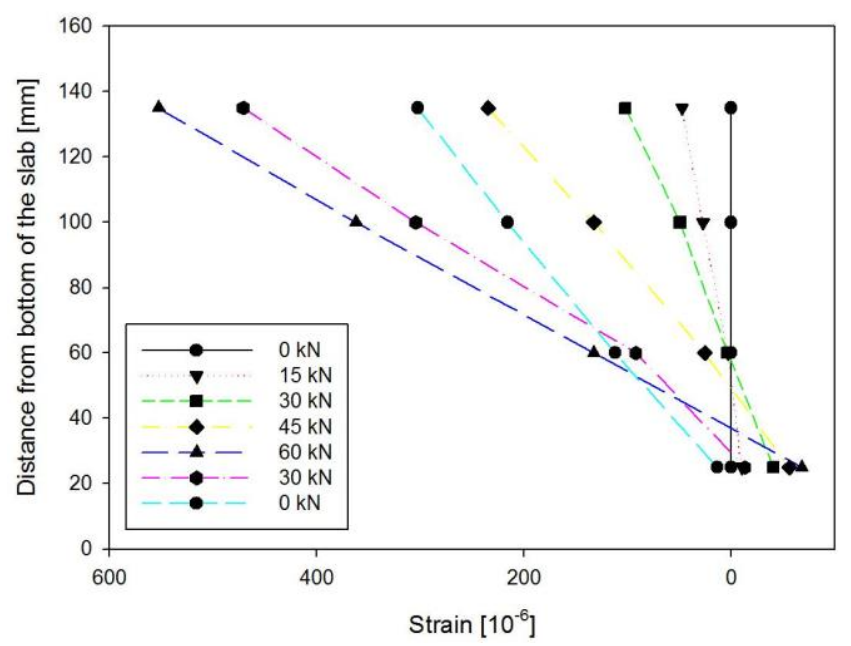

Fig. 11 Strain development measured by DEMECs (Fig. 5(b)) at the central support, Phase 1 


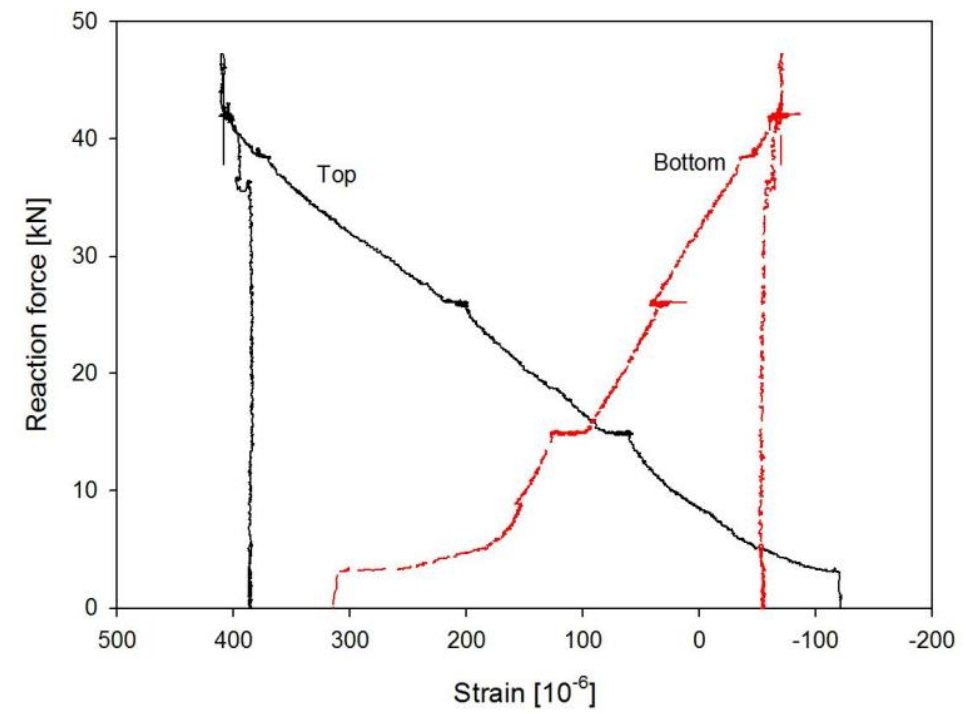

Fig. 12 Strain development measured by electronic deformation gauges (Fig. 5a) at the central support, Phase 2

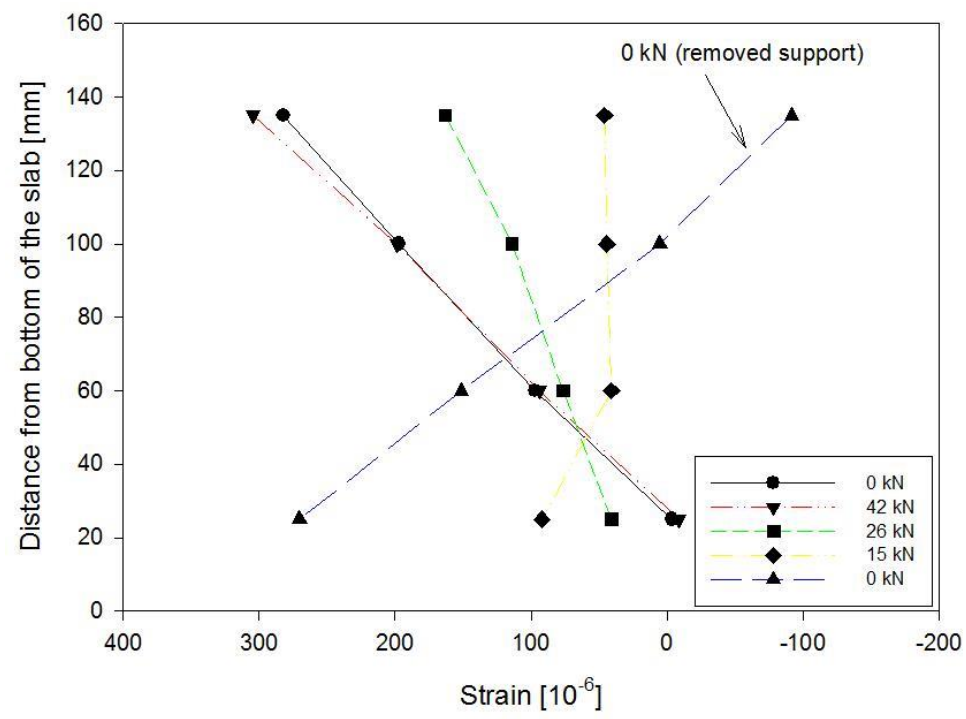

Fig. 13 Strain development measured by DEMECs (Fig. 5(b)) at the central support, Phase 2

During phase 1, the slab's top face was stretched due to the hogging moment over the central support (Fig. 10). Accordingly, the bottom face was subjected to compression. In Fig. 11 it can be noticed that strains increased gradually until the service load $(60 \mathrm{kN})$ was reached. At this load, strains of $550 \times 10^{-6}$ (tension) were observed, whereas the bottom face developed a maximum strain of $-70 \times 10^{-6}$ (compression).

Figs. 12 and 13 illustrate the strain development during phase 2 (removal of the central support). 


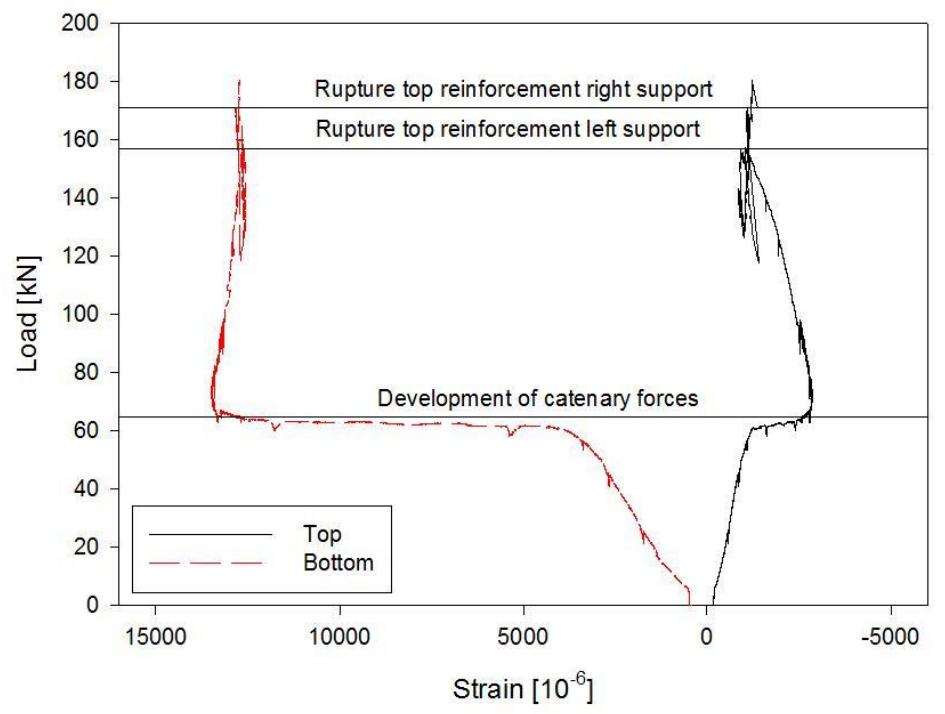

Fig. 14 Strain development (mean value) strain gauges, mid-span, Phase 3

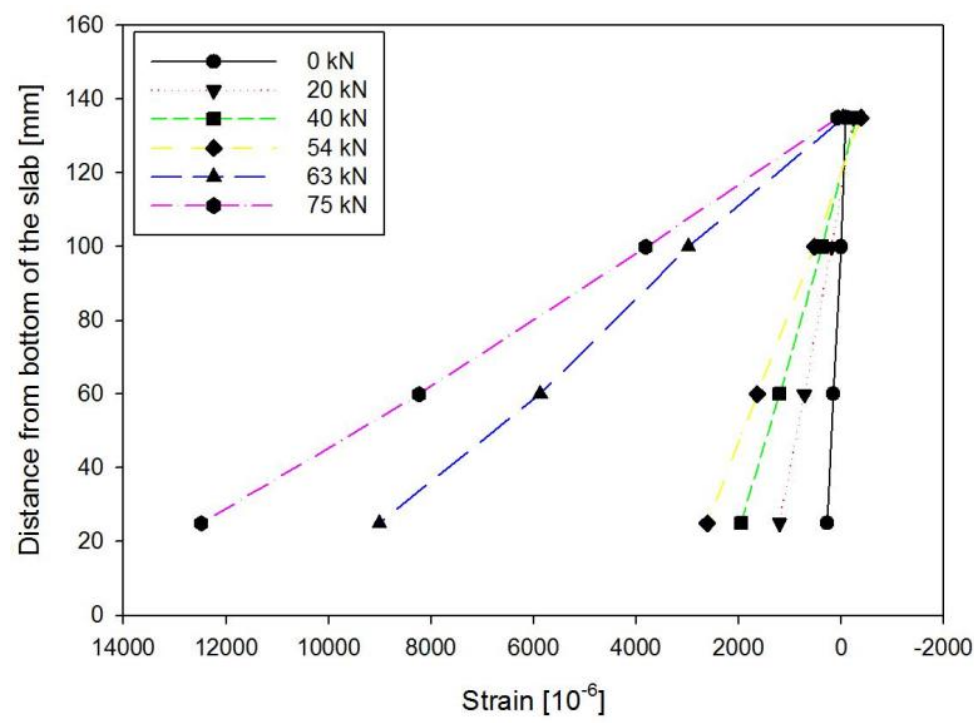

Fig. 15 Strain development (mean value) DEMECs, mid-span, Phase 3

When the specimen was lifted up, at the central support, a maximum reaction force of $42 \mathrm{kN}$ was observed. Tensile strains developed at the top, compressive strains at the bottom side of the slab (see Fig. 12). However, when the reaction force was gradually reduced, the strains at the top fibre switched to shortenings, whereas tensile strains on the bottom side occurred. Fig. 13 shows the strains at different depths and load steps. After the removal of the central support, strains equal to $-92 \times 10^{-6}$ at the top fibre and $270 \times 10^{-6}$ at the bottom fibre were measured.

Figs. 14 and 15 illustrate the strain behaviour during the third phase. Digital measurements were feasible until the collapse of the specimen. However, mechanical strain measurements could 


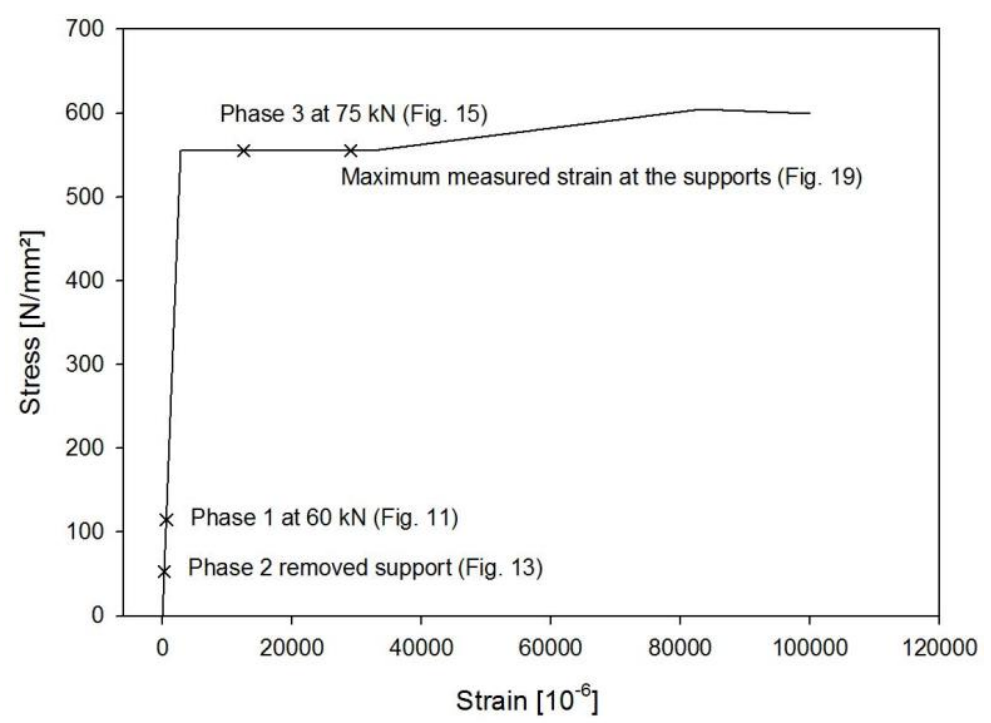

Fig. 16 Tensile strain of reinforcement at different phases and load stages

be taken only until a deflection of around $200 \mathrm{~mm}$ under the line loads.

Initially, the strain behaviour was observed to be linear (see Fig. 14). With further load application, however, yielding of the top reinforcement bars and subsequent development of plastic hinges occurred over the inner supports. Due to this behaviour, the outer edges of the slab strip tended to move inwards and the contact between the specimen and the restraining concrete blocks was established at a vertical load of around $62 \mathrm{kN}$. Tensile membrane behaviour forced the load-displacement curve to increase significantly (Fig. 8, path 1-2) and a catenary stage was introduced. Tensile strains at the bottom side of the specimen stayed at approximately the same level, whereas compressive strains at the top face of the specimen decreased. However, this tendency stopped at the rupture of the reinforcement as indicated in Fig. 14. At a load of $75 \mathrm{kN}$ (Fig. 15), a strain of $12.5 \times 10^{-3}$ was measured at the bottom side, whereas the top face developed a tensile strain of $73 \times 10^{-6}$ at the measuring location.

Fig. 16 illustrates the stress-strain relationship of the reinforcement bars schematically. Further, the tensile strains measured by demountable mechanical strain gauges (see Fig. 5(b)) at the location of the reinforcement at mid-span are indicated on this graph both for the location of the top and bottom reinforcement and during different phases of the loading procedure. For phase 1 the strain at $60 \mathrm{kN}$ (service load) at the top reinforcement and in case of phase 2 the strain in the bottom reinforcement after the removal of the central support are located in the elastic range. However, at a load of $75 \mathrm{kN}$ in phase 3 the bottom reinforcement yielded and its strain can be seen to be located in the horizontal yield plateau. Further, the maximum strain which was able to be measured by the electronic measurements (stopped at $171 \mathrm{kN}$ ) at the location of the inner supports is also illustrated (Fig. 19). Hence, the latter corresponds with the strain observed at $171 \mathrm{kN}$ in case of the top reinforcement at the right inner support.

\subsection{Strain development at the inner supports}

The rupture of the reinforcement bars over the inner supports has shown that these sections 


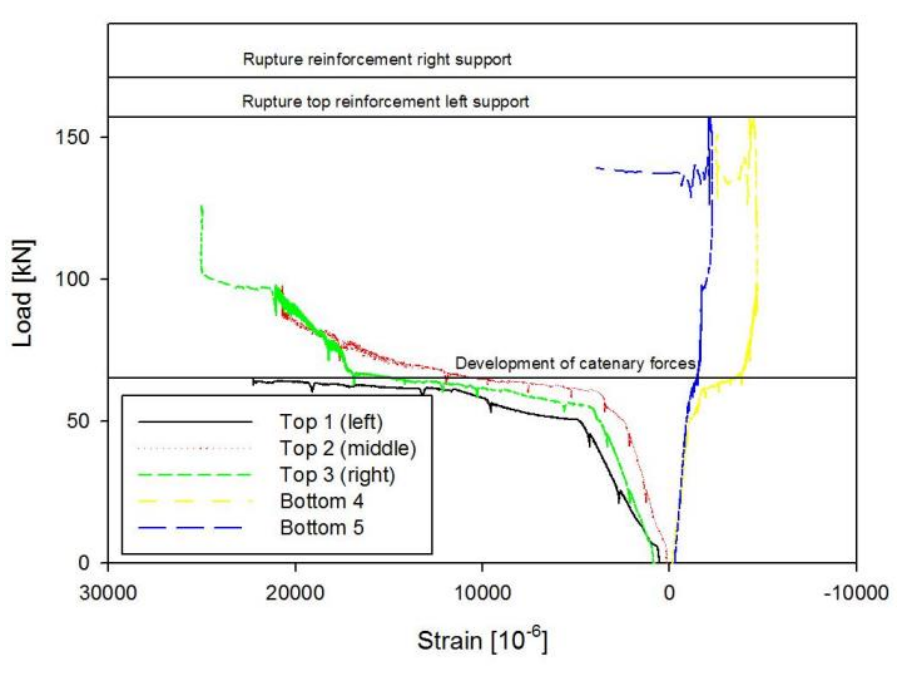

Fig. 17 Strain development left support, Phase 3
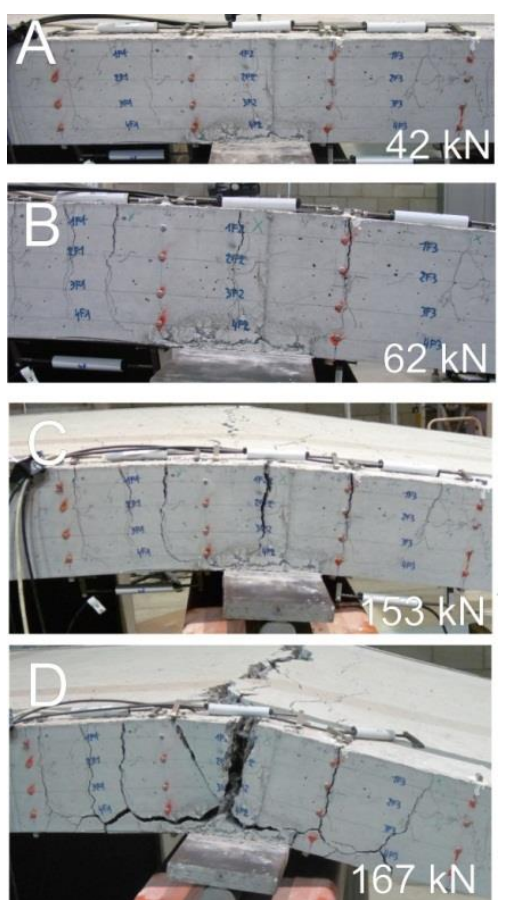

Fig. 18 Deformation and cracks left support, Phase 3

were of particular importance with respect to the collapse resistance of the specimen. Once the top reinforcement was broken, the bottom reinforcement had to take over the tensile forces (involving the formation of very large crack openings and strains). Hence, the description of the strain and cracking development at the inner supports is very important from the viewpoint of future modelling perspectives.

Figs. 17 and 19 illustrate the development of strains over the left as well as over the right support in the third phase (displacement controlled loading until failure). The designation of the measurement locations were chosen according to Fig. 5(a). Both sides of the specimen initially showed an approximately linear strain development. However, the formation of plastic hinges over the supports was accompanied by the formation of large cracks and resulted in a non-linear strain behaviour. Accordingly, the outer edges of the specimen tended to move inwards. However, the inward movement was restrained by use of anchorage blocks as can be seen in Fig. 4. This behaviour can also be observed in the strain diagrams (Figs. 17 and 19).

In the graphs (Figs. 17 and 19) three distinct parts can be observed: The development of tensile membrane forces, the rupture of the top reinforcement over the left support and the rupture of the top reinforcement over the right support. Considering the strain behaviour at the top side of the specimen, a maximum strain of around $29 \times 10^{-3}$ was measured over the right support (Fig. 19, Top 1 (left)) when the top reinforcement over the left support was ruptured. However, the applied measurement equipment (Electronic deformation gauges (Fig. 5(a))) measured the strain over a distance of $200 \mathrm{~mm}$. Strain peaks in the reinforcement, such as at crack openings could not be measured. After the rupture of the top reinforcement bars, the bottom reinforcement had to take over the entire tensile force accompanied with the formation of tensile strains (cf. line Bottom 5, 


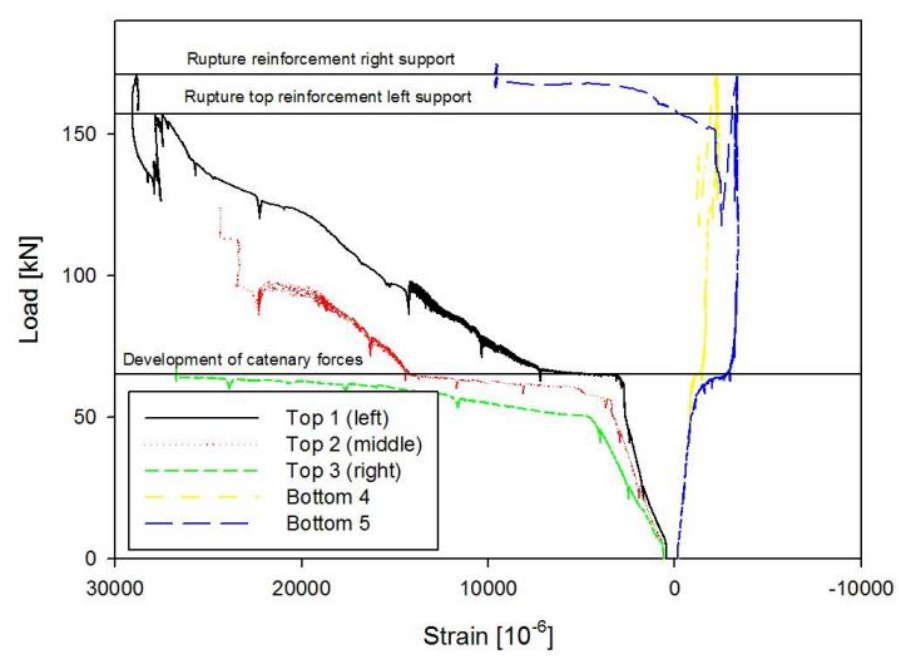

Fig. 19 Strain development right support, Phase 3
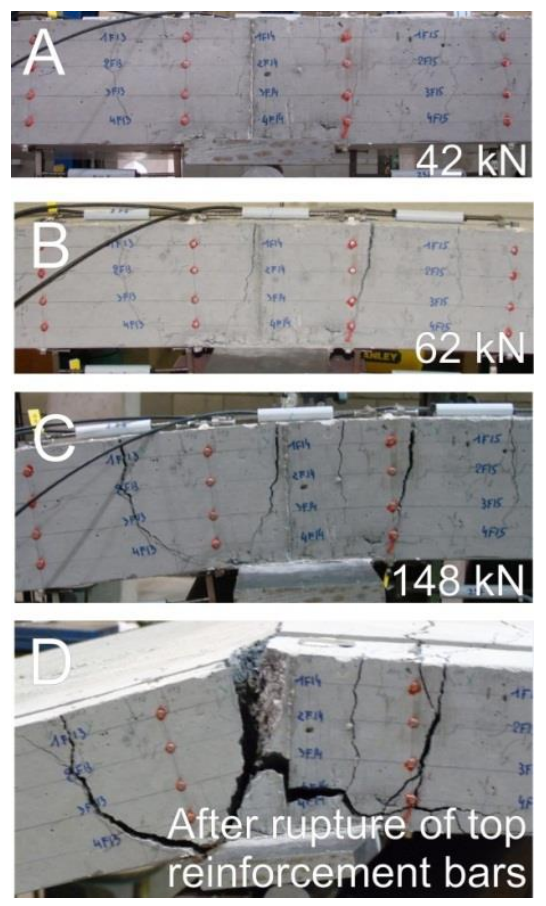

Fig. 20 Deformation and cracks right support, Phase 3

Fig. 19).

Figs. 18 and 20 illustrate the deformation of the specimen at the location of the inner supports for different load levels, which can be located in the strain diagrams (Figs. 17 and 19) by use of load designations. A and B (Fig. 18 and 20) are giving information about the deformation in the linear loading phase as well as shortly before the formation of tensile membrane forces, respectively. C and D are illustrating the cracking behaviour in stages of more advanced deformation.

\subsection{Crack development}

The crack development of the largest crack openings during phase 3 is illustrated in Figs. 21 (left support) and 22 (right support) until a load of $120 \mathrm{kN}$. It was observed that all major flexural cracks persisted transverse to the longitudinal axis developing over the full width of the specimen. However, at stages of higher deformation of the inner supports, also horizontal cracks appeared at the level of the reinforcement (see pictures D in Figs. 18 and 20).

Measurements of crack widths were feasible until a displacement under the line loads of 200 $\mathrm{mm}$ on the frontside and $280 \mathrm{~mm}$ on the backside of the specimen. Both sides confirmed an increase in crack width after the formation of plastic hinges and subsequent development of tensile membrane forces. At a load of $123 \mathrm{kN}$ the most severe cracks were measured to have an opening of around $5.5 \mathrm{~mm}$. 


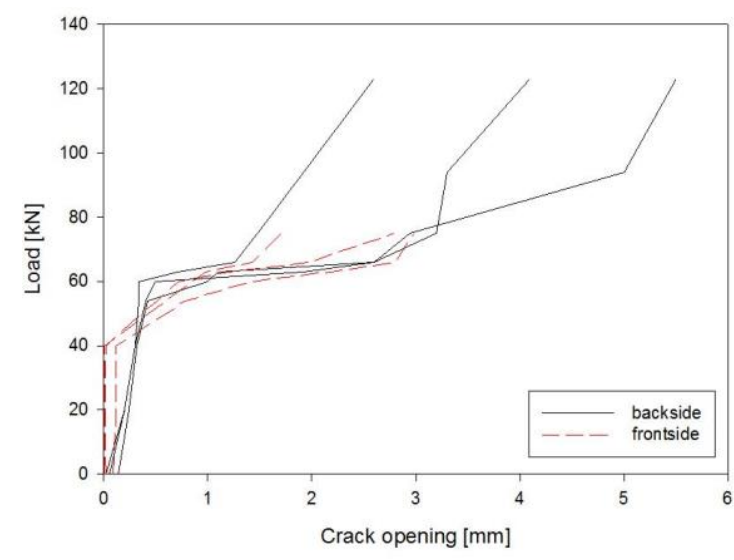

Fig. 21 Crack development left support, Phase 3

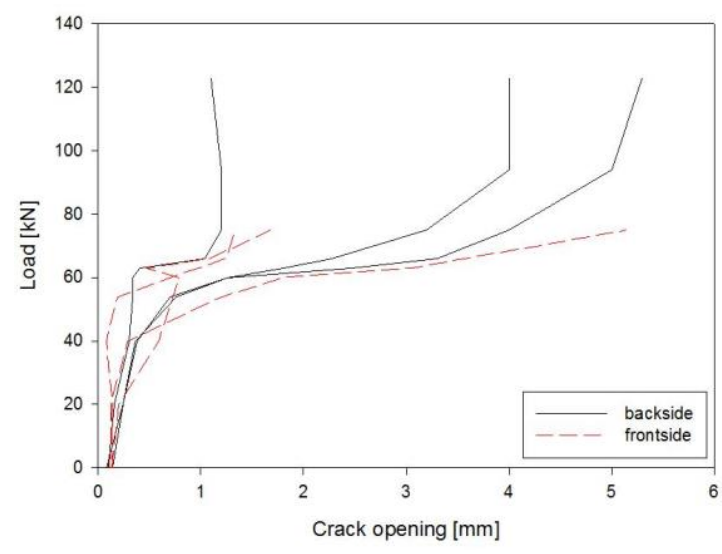

Fig. 22 Crack development right support, Phase 3

\section{Failure mode}

Fig. 23 shows the right inner support after collapse, which was ultimately induced by the tensile failure of the reinforcement bars in a crack over one of the supports, where plastic hinges developed. Hence, the failure mechanism is predominantly related to bending in combination with the rupture of the steel reinforcement at high strain deformations, which was confirmed by the experimental observations after testing.

In order to establish the redistribution of stresses, sufficient rotation capacity of the specimen has to be available. It was the rotation capacity of the sections over the supports that created the necessary deformations to allow for the beneficial effect of catenary behaviour.

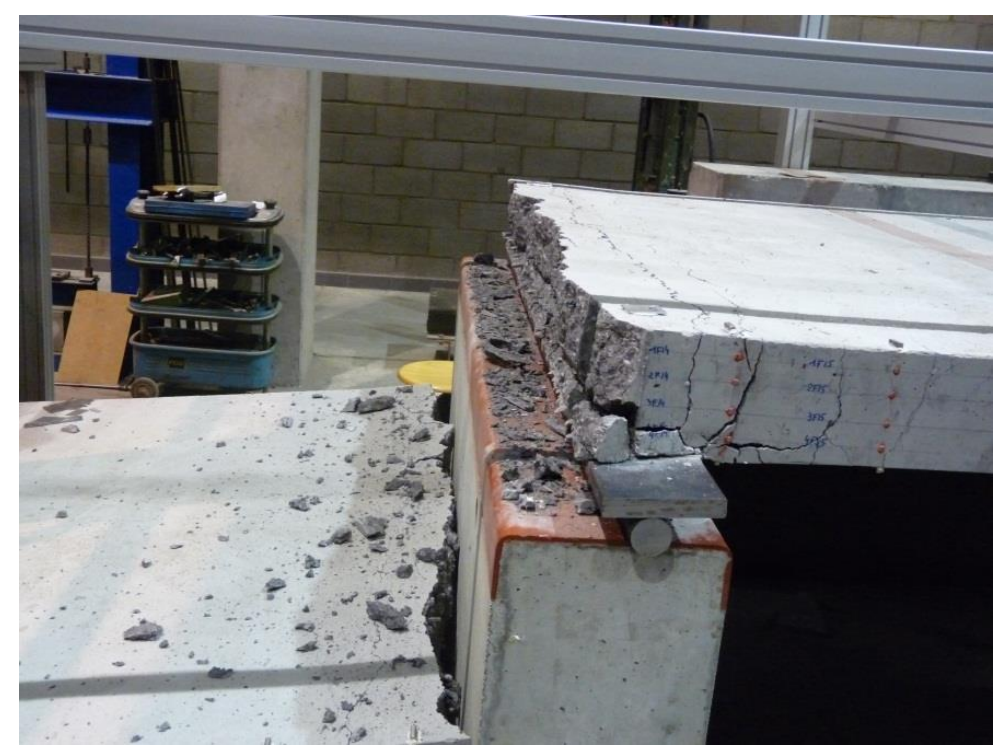

Fig. 23 Failure of the specimen due to complete rupture of the longitudinal reinforcement at the right inner support 


\section{Conclusions}

In order to investigate tensile membrane behaviour in reinforced concrete slab strips, a realscale experiment has been conducted. The laterally restrained specimen exposed to a simulated failure of the central support withstood a transverse load that was $300 \%$ of the service load associated to the shorter spans before removal of the central support. This favourable effect was solely due to tensile membrane behaviour forcing the load-displacement curve to increase significantly when entering the catenary stage. It was shown, that tensile strains of the specimen remained at approximately the same level, whereas compressive strains on the opposing face of the specimen reduced.

Further, the collapse of the reinforced concrete specimen was eventually controlled by the rupture of the reinforcement bars at the location of the inner supports. As a result, the collapse resistance is strongly dependant on the ductility of the reinforcing steel bars and as such from the rotation capacity of the concrete section over the support. In case the maximum strain capacity of one reinforcement bar is exceeded, membrane stresses have to be redistributed over all other reinforcement bars in a certain layer, most often resulting in an almost instantaneous rupture of all reinforcement bars in the layer. It was demonstrated that the bottom reinforcement bars over the inner supports could take over the tensile forces without causing the specimen to fail in a brittle way. However, the collapse was finally induced by the rupture of the bottom reinforcement. Detailed observations with respect to the strain and crack development under catenary action were described. These latter observations are of particular importance with respect to future research towards numerical modelling of catenary and membrane action in concrete slabs.

\section{Acknowledgments}

This research has been made possible through funding from the Research Foundation Flanders (FWO) through research grant G.0822.09N "Theoretical and experimental study of membrane actions in the framework of robustness analyses of concrete structures", which is gratefully acknowledged.

\section{References}

Amir, S., van der Veen, C., Walraven, J.C. and de Boer, A. (2012), "Punching shear strength of concrete decks", Proceedings of the International Conference on Advanced Concrete Technology and its Applications (ACTA-2012), Islamabad, Pakistan, November.

Bailey, C.G. (2001), "Membrane action of unrestrained lightly reinforced concrete slabs at large displacements", Eng. Struct., 23(5), 470-483.

Bailey, C.G., Toh, W.S. and Chan, B.M. (2008), "Simplified and advanced analysis of membrane action of concrete slabs", ACI Struct. J., 105(1), 30-40.

CEN (European Committee for Standardization (2002), Eurocode: Basis of structural design, CEN, Brussels.

CEN (European Committee for Standardization (2006), Eurocode 1: Actions on structures: Part 1-7: Accidental actions, CEN, Brussels.

Gouverneur, D., Caspeele, R. and Taerwe, L. (2013), "Experimental investigation of the load-displacement behaviour under catenary action in a restrained reinforced concrete slab strip", Eng. Struct., 49, 1007- 
1016.

Hayes, B. (1968), "Allowing for membrane action in the plastic analysis of rectangular reinforced concrete slabs", Mag. Concrete Res., 20(65), 205-212.

Johansen, K.W. (1962), Yield-Line Theory, Cement and Concrete Association, London, United Kingdom.

Li, G.Q., Guo, S.X. and Zhou, H.S. (2007), "Modeling of membrane action in floor slabs subjected to fire", Eng. Struct., 29(6), 880-887.

Muthu, K.U., Amarnath, K., Ibrahim, A. and Mattarneh, H. (2007), "Load deflection behaviour of partially restrained slab strips", Eng. Struct., 29(5), 663-74.

Ockleston, A.J. (1955), "Load tests on a 3-story reinforced concrete building in Johannesburg", Struct. Eng., 33(10), 304-322.

Park, R. (1964), "Tensile membrane behaviour of uniformly loaded reinforced concrete slabs with fully restrained edges", Mag. Concrete Res., 16(46), 39-44.

Westergaard, H.M. and Slater, W.A. (1921), "Moments and stresses in slabs", ACI Struct. J., 17(2), 415539.

Wood, R.H. (1961), Plastic And Elastic Design Of Slabs And Plates, With Particular Reference To Reinforced Concrete Floor Slabs, Thames and Hudson, London, United Kingdom.

$\mathrm{Yu}$, J. and Tan, K.H. (2011), "Experimental and numerical investigation on progressive collapse resistance of reinforced concrete beam column sub-assemblages", Eng. Struct., 139, 233-250.

$C C$ 